\title{
Comparison of the Tru-cut biopsy needle with the Abrams punch for pleural biopsy
}

\author{
D T MCLEOD, I TERNOUTH, N NKANZA \\ From the Departments of Medicine and Histopathology, Godfrey Huggins School of Medicine, University of \\ Zimbabwe, Harare, Zimbabwe
}

ABSTRACT In a prospective study pleural biopsy specimens obtained with a Tru-cut needle were compared with those obtained with an Abrams pleural biopsy punch from 36 patients in Zimbabwe judged to have an effusion of at least 1.5 litres; one patient had two biopsies. Both instruments were used on each patient, the Abrams punch being followed by the Tru-cut needle. There were no serious complications. The diagnoses determined by biopsy were: tuberculosis (11); carcinoma (12); chronic inflammation (9); and pleural fibrosis (4); one biopsy showed nothing abnormal. In $23(62 \%)$ patients both biopsy needles produced adequate diagnostic material; in eight the Tru-cut needle alone produced diagnostic material and in six the Abrams punch alone. Thus diagnostic material was obtained in 31 patients from the Tru-cut needle and in 29 from the Abrams punch. The Tru-cut needle was useful and safe for pleural biopsy in this series and appeared to be particularly useful when the pleura was thickened.

\section{Introduction}

Pleural effusion is a manifestation of many common medical conditions; most of them prove to be benign, but in every case the main concern is to exclude malignancy and tuberculosis. The Abrams punch' is the instrument used most widely in Britain for pleural biopsy. ${ }^{2} \mathrm{~A}$ blunter instrument, such as a Cope needle, ${ }^{3}$ may be more suitable when little or no pleural fluid is present but this instrument is rarely found in general medical wards in British hospitals. Closed pleural biopsy using a Cope or Abrams punch offers a diagnosis in $57-80 \%$ of tuberculous effusions ${ }^{4}$ and in $48-70 \%$ of cases of neoplasia. ${ }^{5}$ The general consensus is that cytological examination of the fluid greatly increases the diagnostic yield in malignant disease ${ }^{6}$ but that a pleural biopsy with tissue culture remains the optimal means of diagnosing a tuberculous effusion. Surprisingly, non-specific changes usually account for most cases, up to $68 \%$ of reports in one series. ${ }^{7}$ Obtaining an adequate sample of pleural tissue is clearly the main requirement of any biopsy procedure. When closed biopsy fails thoracoscopy is a useful diagnostic procedure as it is simple and well tolerated

Address for correspondence: Dr D T McLeod, Sandwell District General Hospital, West Bromwich, West Midlands B71 4HJ. (Reprints will not be available.)

Accepted 12 July 1989 and has a diagnostic yield of $95 \%$, but it suffers the $\stackrel{\circ}{\mathcal{Q}}$

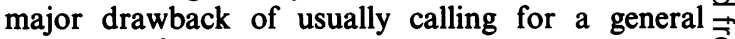
anaesthetic. ${ }^{8}$

The Tru-cut needle has been used primarily for biopsy of solid lesions, lymph nodes, and breast lumps and for routine liver and renal biopsies. It is a thin, disposable instrument with a sharp cutting edge, which we thought might prove useful for biopsies of $\underset{\sim}{\mathbb{X}}$ thickened pleura. We report the findings of a prospec- $-\dot{-}$ tive study comparing it with the well established 3 . Abrams punch.

\section{Methods}

Patients admitted to the medical wards at the Harare $\frac{D}{0}$ Central Hospital during March-June 1987 with a moderate to large pleural effusion were studied pros- $\sigma$ pectively. Patients with small effusions, estimated to be N less than 1.5 litres, were not entered into the study.

After the skin had been cleaned with iodine solu- $\omega$ tion, $2 \%$ lignocaine was used to anaesthetise the skin and subcutaneous tissue down to the pleura, a $21 \stackrel{\circ}{\circ}$ gauge needle being used. By withdrawing the needle to the skin and reintroducing it at an angle a length of ${ }_{7}^{-}$ about $2 \mathrm{~cm}$ of pleura was anaesthetised. A $0.5 \mathrm{~cm}-$ incision through skin and muscle was made and three $\vec{D}$ Abrams biopsy specimens were taken at different sites, $\frac{?}{\mathbb{D}}$ as described by Raja and Lalor. ${ }^{9}$ The Tru-cut needle $\propto$ was then introduced carefully through the same? 
incision at $45^{\circ}$ to the skin in the direction of the chosen intercostal space above the lower rib to the depth indicated previously by the fluid aspiration with the 21 gauge needle. The same puncture site could be used as the Abrams punch obtains pleura from the region around the hole in the pleura whereas the Tru-cut needle tends to take pleural tissue more distally from the entry site. Thus adjacent areas of pleura were sampled. A definite "give" indicated entry into the pleural space and was confirmed by the ease of advancement of the inner stilet. The Tru-cut needle as a whole was angled towards the skin (position A to B, figure), allowing the inner stilet to be advanced along the inner aspect of the chest wall and away from the lung (figure). The outer cutting sheath was then advanced over the inner stilet, resulting in biopsy of up to $2 \mathrm{~cm}$ of parietal pleura and intercostal muscle. The procedure was repeated if an adequate specimen was not obtained. This technique was learned by careful practice on cadavers: the Tru-cut is much sharper than an Abrams punch and the clinician, used to having to push very firmly with the Abrams punch, needs to know how a Tru-cut feels and appreciate the more gentle sensation of the "give" as the pleural space is entered. Care was taken to biopsy in the line of the ribs to avoid the neurovascular bundles.

The specimens were placed in two separate tubes, labelled A and B, containing $10 \%$ formal saline; the biopsy needle corresponding to each letter was recorded separately. Culture for Mycobacterium tuber- culosis was not possible in this study. The tissues were embedded in wax and $4 \mu \mathrm{m}$ sections were made. All specimens had three sections taken and stained with haematoxylin and eosin. Sections were examined microscopically by $\mathrm{NN}$, who was unaware of the coding. For comparison of the two specimens particular attention was paid to the quantity of tissue, the presence of pleura, and the diagnostic value of the biopsy.

\section{Results}

During the five months of the study 36 patients were studied; one patient required a repeat biopsy. Twenty seven were male (mean age 49 , range $10-70$ years) and nine were female (mean age 48 , range $26-70$ years). There were no major complications. No patient required insertion of a chest drain for pneumothorax. The two operators found the Tru-cut biopsy much easier to perform, because the instrument is thinner and sharper.

Overall, Tru-cut biopsy specimens were thought to be better than Abrams in 25 of the 37 biopsies. Details are shown in the table. With the Abrams punch 29 of the 37 procedures yielded diagnostically adequate material compared with 31 of the 37 with Tru-cut needle (difference not significant). The Tru-cut provided a greater amount of pleura when the pleura was greatly thickened, as in tuberculosis and in the one case of probable mesothelioma.

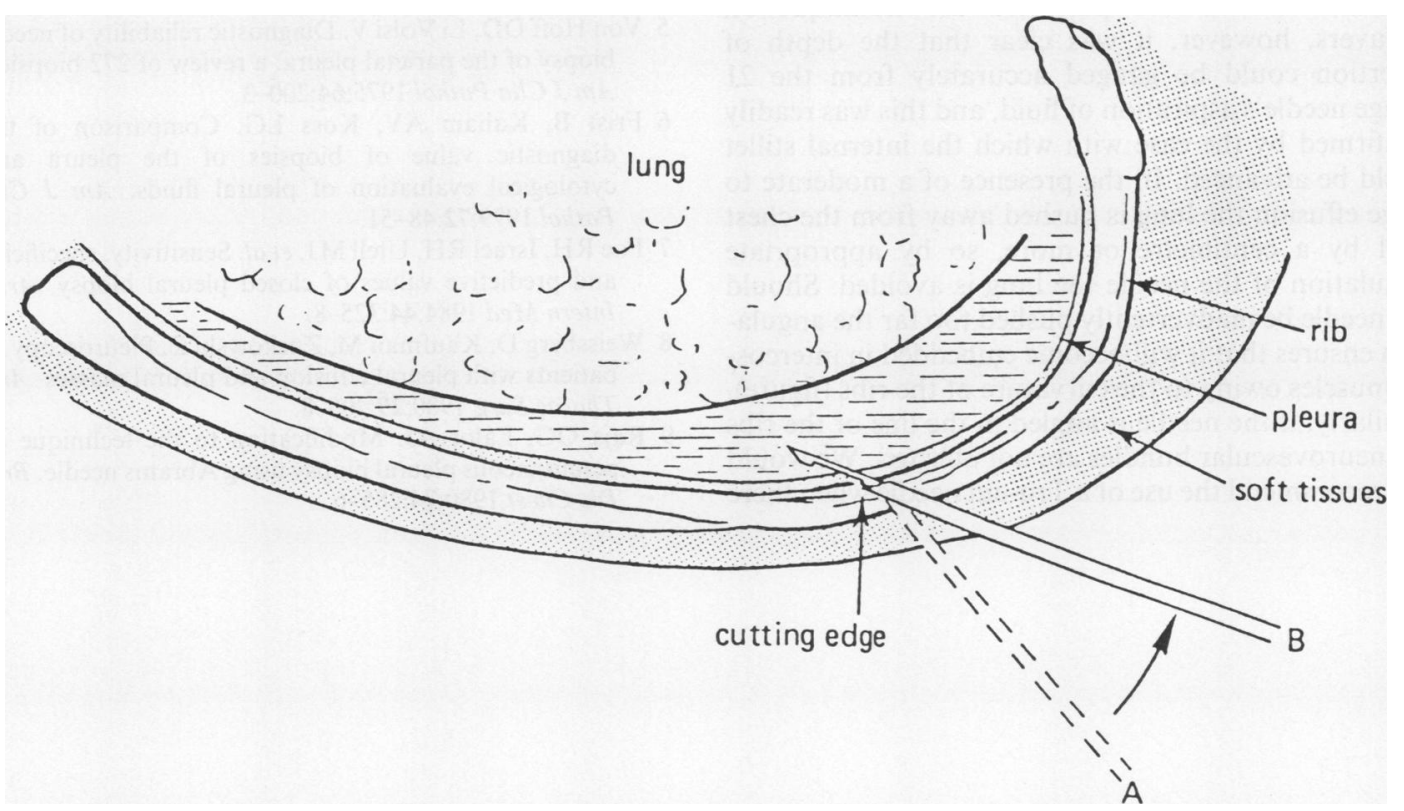

Cross section through the sixth intercostal space, showing the position of the open Tru-cut needle just before a biopsy specimen is taken. 
Comparison of the efficacy of the Tru-cut and Abrams biopsy punch

\begin{tabular}{|c|c|c|c|c|}
\hline \multirow[b]{2}{*}{ Disease } & \multicolumn{2}{|c|}{$\begin{array}{l}\text { Both methods } \\
\text { diagnostic }\end{array}$} & \multirow{2}{*}{$\begin{array}{l}\text { Abrams } \\
\text { only } \\
\text { diagnostic }\end{array}$} & \multirow{2}{*}{$\begin{array}{l}\text { Tru-cut } \\
\text { only } \\
\text { diagnostic }\end{array}$} \\
\hline & $\begin{array}{l}\text { Abrams } \\
\text { better }\end{array}$ & $\begin{array}{l}\text { Tru-cut } \\
\text { better }\end{array}$ & & \\
\hline $\begin{array}{l}\text { Tuberculosis } \\
\text { Carcinoma } \\
\text { Chronic inflammation } \\
\text { Pleural fibrosis } \\
\text { Normal }\end{array}$ & $\begin{array}{l}1 \\
2 \\
1 \\
2 \\
0\end{array}$ & $\begin{array}{l}5 \\
6 \\
4 \\
1 \\
1\end{array}$ & $\begin{array}{l}0 \\
4 \\
2 \\
0 \\
0\end{array}$ & $\begin{array}{l}5 \\
0 \\
2 \\
1^{*} \\
0\end{array}$ \\
\hline Total & 6 & 17 & 6 & 8 \\
\hline
\end{tabular}

*Probable mesothelioma.

\section{Discussion}

This study has shown that the Tru-cut biopsy needle is a useful alternative to the Abrams punch. The main disadvantages of the Abrams biopsy punch are that it has a wide bore and is often blunt and the inner cutting tube often has a poor fit, allowing leakage of fluid and, more importantly, air; it is also fairly cumbersome. It does, however, allow aspiration of pleural fluid, confirming that the needle has entered the pleural space. Several methods have been adopted in an attempt to ensure that pleural biopsy specimens are adequate. ${ }^{9}$ The Tru-cut may appear to be unsuitable for pleural biopsy because there is no facility for aspiration of fluid to confirm entry into the pleural space. After we had perfected the technique on cadavers, however, it was clear that the depth of insertion could be gauged accurately from the 21 gauge needle's aspiration of fluid, and this was readily confirmed by the ease with which the internal stillet could be advanced. In the presence of a moderate to large effusion the lung is pushed away from the chest wall by a centimetre or more, so by appropriate angulation of the needle the lung is avoided. Should the needle be inadvertently pushed too far the angulation ensures that it will become embedded in intercostal muscles owing to the curvature of the ribs (figure). Similarly, if the needle is angled in the line of the ribs the neurovascular bundles are not affected. We would not recommend the use of a Tru-cut needle when there is little fluid for fear of lacerating the lung, liver, or spleen.

The Tru-cut needle proved to be particularly useful in the presence of thickened pleura, such as is found in tuberculosis. In this study the Abrams biopsy punch failed to yield a diagnosis of five cases of tuberculous pleurisy, and the Tru-cut had a similar failure rate in patients with carcinoma. When the pleura is thickened by a malignant process such as mesothelioma there is no need to angle the Tru-cut needle as the risk of pneumothorax is minimal, the lung usually being affected by the disease process. A final consideration is the patient's preference. Owing to its sharpness and thin calibre, the Tru-cut needle was simple, safe, and well tolerated.

We thank Mr R S Watson and Travenol Laboratories Ltd for donating Tru-cut biopsy needles for the study and Catharine Gow for secretarial assistance.

\section{References}

1 Abrams LD. A pleural biopsy punch. Lancet 1958;i:30-1.

2 Iles PB, Ogilvie C. Procedures in practice. Pleural aspiration and biopsy. $\mathrm{Br}$ Med J 1980;i:693-5.

3 Cope C. New pleural biopsy needle. JAMA 1958;167:1107-8.

4 Scharer L, McClement JH. Isolation of tubercle bacilli from needle biopsy specimens of parietal pleura. $\mathrm{Am}$ Rev Respir Dis 1967;97:466-8.

5 Von Hoff DD, Li Volsi V. Diagnostic reliability of needle biopsy of the parietal pleura: a review of 272 biopsies. Am J Clin Pathol 1975;64:200-3.

6 Frist B, Kaham AV, Koss LG. Comparison of the diagnostic value of biopsies of the pleura and cytological evaluation of pleural fluids. Am J Clin Pathol 1979;72:48-51.

7 Poe RH, Israel RH, Utell MJ, et al. Sensitivity, specificity and predictive values of closed pleural biopsy. Arch Intern Med 1984;44:325-8.

8 Weissberg D, Kaufman M, Zurkowski Z. Pleuroscopy in patients with pleural effusion and pleural masses. Ann Thorac Surg 1980;29:205-8.

9 Raja OG, Lalor AJ. Modification to the technique of percutaneous pleural biopsy using Abrams needle. $B r J$ Dis Chest 1980;74:285-6. 